\title{
Human Resource Management practitioners' responses to workplace bullying: \\ Cycles of symbolic violence
}

Susan Harrington, School of Management, University of Leicester, UK

Samantha Warren, Essex Business School, University of Essex, UK

Charlotte Rayner, Portsmouth Business School, University of Portsmouth, UK

\begin{abstract}
In the United Kingdom the majority of those reporting being bullied at work claim their manager as 'the bully' (Hoel and Beale, 2006). A global phenomenon, workplace bullying is damaging to those involved and hence their organizations (Einarsen et al., 2003), justifying academic attention and a practical need to develop mechanisms that tackle the phenomenon. Bullying is typically a problem 'owned' by Human Resource (HR) departments, yet existing evidence suggests that targets perceive HR practitioners (HRPs) as inactive, hence ineffective, in response to claims (Lewis and Rayner, 2003). However, very little is known about how HRPs themselves interpret and respond to claims of bullying. We address this gap, drawing on Bourdieu's concept of 'symbolic violence' to interpret experiential interview data. Our findings suggest HRPs enact symbolic violence on employees who raise claims of bullying against their managers by attributing managerial bullying behaviours to legitimate performance management practices. A critical discourse analysis identified four interpretive mechanisms used by HRPs that served to exonerate managers from bullying behaviours, thereby protecting the interests of the organization at the expense of an employee advocacy role. These data suggest that, rather than being solely a phenomenon perpetrated by individuals, workplace bullying is often a symptom of managerialist and capitalistic discourses of intensified performance management in organizations, reinforced by the embedding of existing professionalization discourses with the field of Human Resource Management in the UK.
\end{abstract}

Keywords: Bourdieu, Critical Discourse Analysis, HRM, Human Resource Management, Workplace bullying, intervention, managerialism, performance management, symbolic violence. 


\section{Introduction}

'Workplace bullying' describes persistent negative behaviours perpetrated by one or more individuals on a less powerful 'target' who is often unable to defend themselves (Einarsen et al., 2003). In the UK, the majority of employees' claims of bullying are against their managers (Hoel and Beale, 2006). Hence, although co-workers or subordinates may also perpetrate bullying, it is the claims against managers that are the focus for this article. Whilst a significant body of research on this phenomenon has greatly contributed to understanding the associated individual and organizational factors, bullying remains prevalent within organizations (Einarsen et al., 2010). The impacts of bullying on employees are wide-reaching and significant (Hogh et al., 2010), as are the financial costs to organizations (Giga et al., 2008). Thus, we start from the position that workplace bullying is a resistant and pernicious aspect of organizational life for a significant number of employees.

Despite the predominance of Human Resource practitioners' (HRPs') involvement in dealing with bullying claims (Salin, 2008) and the importance of their response in determining how targets cope with their bullying experience (D'Cruz and Noronha, 2010), little is known about how HRPs interpret and respond to employees' claims. We address this gap by drawing on qualitative interview data generated during a wider research project on workplace bullying, to explore how HRPs interpret and respond to employees' claims that their manager is bullying them, from here on referred to as 'manager-to-employee bullying claims'.

Importantly, we posit that understanding the phenomenon of workplace bullying requires an analysis that extends beyond the conscious acts of individuals to 
encompass the socio-economic fabric of contemporary organizational life. In order to undertake this, we draw on key constructs from Pierre Bourdieu's Theory of Practice, including shared habitus, doxa, capital and in particular symbolic violence, as tools to analyse the complexity of HRPs' organizationally and professionally embedded experiences of dealing with bullying claims. Specifically, our analysis examines the impact of power on, in and through HRPs and questions their role in producing and sustaining organizational realities that are increasingly characterized by discourses and practices that are in and of themselves 'bullying'.

Within a Bourdieusian framework, we present interview data from HRPs about their practices and experiences of dealing with bullying claims. By applying Bourdieu's constructs of shared habitus and, in particular, symbolic violence to our critical discourse analysis of the HRPs' language, we examine the balance of power between managers and HRPs in manager-to-employee bullying claims, particularly within the professional context of Human Resource Management (HRM) in the UK. This contributes significantly to the field of organizational bullying, since no previous studies have investigated how bullying claims are interpreted and subsequently acted upon from an HRP's perspective. Moreover, and importantly for our purposes here, our analysis also make a nuanced empirical contribution to hitherto conceptual debates around whether bullying may be produced and perpetuated by the powerimbued management and HRM practices that comprise organizational life (Brodsky, 1976; Rhodes et al., 2010).

We begin by giving a necessarily concise overview of the contested nature of workplace bullying to demonstrate the importance of examining the HRPs' 
perspective, before providing a précis of the constructs of Bourdieu's theory of practice drawn upon in this study. Subsequently, we present the study methodology and findings, followed by a discussion that lays out our framing of these data as organizational bullying. We conclude the article by suggesting practical recommendations and directions for future research.

\section{Workplace bullying and HRM practice}

Within the UK context of this research, predominantly survey-based research suggests that the prevalence of self-reported bullying is between 10 to $35 \%$ within the UK workforce, with the majority of this being manager-to-employee bullying (Beale and Hoel, 2010). Whilst bullying is not legally defined within employment law in the UK, approximately $80 \%$ of organizations have an anti-bullying policy describing the behaviours that constitute bullying and the informal and formal resolution routes available to employees (CMI, 2008). Provision of these policies and dealing with bullying claims are firmly within the remit of HRM; thus, HRPs have a critical role in identifying, preventing and resolving bullying in organizations (Lewis and Rayner, 2003). The professional body for HRM practitioners in the UK - the Chartered Institute of Personnel and Development (CIPD) - provides guidance on anti-bullying policy and HRPs' related practices (CIPD, 2012). In this guidance, workplace bullying is constructed as an individual and interpersonal phenomenon, defined as persistent and frequent negative behaviours between individuals that have a detrimental impact on the target, from which they are powerless to defend themselves or retaliate (e.g., Einarsen et al., 2003). The behaviours may be work-related (e.g., withholding information, excessive workload or monitoring), personal (e.g., spreading rumors, undermining or persistent criticism), or social isolation (Einarsen and Hoel, 
2001). Given the CIPD's near monopoly position in controlling membership to the HRM profession in the UK through its education programmes and continuing professional development requirements (Gilmore \& Williams, 2007), HRPs will be strongly influenced by CIPD guidance.

Notwithstanding the above and specific to this present research, a problematic and incongruent picture emerges in relation to HRPs' related practices: the majority of organizations' anti-bullying policies are written and owned by the HR department and stipulate that an employee's route for raising an allegation of bullying is through the HR function. Thus, HRPs are pivotal in providing the policy and progressing claims (Rayner and Lewis, 2010). Consequently, HRPs are crucial to the employee's perception of how justly their claim is handled (Ferris, 2004). Yet, whilst targets report following policy and raising bullying claims with HRPs in the belief it will help their situation (D'Cruz and Noronha, 2010), they often perceive HRPs' responses to these claims as inconsistent with policy, and as inaction, denial, target-blaming or management complicity (e.g. Hutchinson et al., 2009; Lutgen-Sandvik, 2008; Rayner, 2005). Such responses from HRPs can be experienced as further bullying, thereby exacerbating the impact on the target (D'Cruz and Noronha, 2010). Crucially, at the center of this incongruence, it is the HRP who acts as 'gatekeeper' in instigating the organization's anti-bullying policy in response to a new claim: the initiation of a bullying investigation necessitates the HRP upholding the employee's initial allegation specifically as potential bullying. Thus, exploring how HRPs interpret and respond to new bullying claims is critical if we are to develop our understanding of this dissonant picture. 
Little is known about HRPs' responses to bullying claims. Salin's (2008; 2009) survey-based research with Finnish public sector HRPs is the exception. Beyond developing policy, Salin (2008) found HRPs' roles in bullying resolution were predominantly passive. The most commonly reported action to bullying claims was to have "discussions with the parties involved"; punitive measures against the bully were taken in less than 5\% claims, whilst in $12 \%$ the HRPs reported taking no action (Salin, 2009: 35). Beyond Salin's research, we know of no other published empirical examination of HRPs' interpretation of bullying claims and subsequent actions. With the continued prevalence of bullying, despite widespread implementation of antibullying policy, and the central role HRPs play in its resolution, the study we are about to present sought to examine how HRPs interpret bullying claims, and how these interpretations influence their subsequent actions. Specifically, the research questions that underpin this research are as follows:

1. Given their central role in dealing with employees' claims of bullying, how do HRP's interpret, experience and act on these claims?

2. What role do HRPs play in the continued prevalence of negatively experienced bullying behaviours in contemporary organizational life?

Furthermore, because of the predominance of manager-to-employee bullying in the UK, we focus on the point at which an employee raises a new claim of manager-toemployee bullying to an HRP. Before turning to our methodology and findings, however, we first outline the theoretical framework for our study.

\section{Theoretical foundations: Pierre Bourdieu's 'theory of practice'}

Bourdieu's 'theory of practice' provides a framework for understanding the relational nature of social action (in this case responding to a bullying claim) at the individual, 
organizational and broader socio-historical levels (Bourdieu, 1977). Despite the continual development of his constructs, Bourdieu consistently used the analogy of a 'game' as a heuristic device to explicate his theory (Painter, 2000). Bourdieu (1993) conceptualized the field as the arena in which a game takes place between its players; it is a social space structured and organized around specific types of resources, or capital, for which field members compete, such as respect, promotions and high salaries within organizations. Fields have permanence; they are durable across time; they are 'social facts' that exist independently of behaviour or people's perceptions of them (Bourdieu, 1990). Within the fields to which they belong, an individual's power, or capital, is both a weapon to use to their advantage in the game and a stake to be won. The amount and type of capital (economic, social and cultural) an individual possesses determines their relative position in the field. Although not transparent to field members, Bourdieu argued that all forms of capital are "transformed, disguised forms of economic capital" because of the dominance of economic discourses in society (Bourdieu, 1986: 252). Thus, career-related qualifications and extensive professional networks are, for example, instances of cultural and social capital, respectively, because of their economic value in the field. The value of capital is field-dependent and capital that is recognized and legitimized as valuable by the field is symbolic capital. The 'rules of the game', the field's doxa, determine this value and, hence, the field's symbolic capital is the ultimate basis of power (Bourdieu, 1977). Thus, an organizational field is a site of constant struggle and conflict as players seek to maximize their relative position and symbolic capital (Dobbin, 2008).

Doxa comprises the taken-for-granted shared knowledge of the values, practices and associated language of the field. It is through an organization's doxa that shared 
understandings are constructed: an individual's durable internal dispositions, or habitus, enable them to understand the taken-for-granted doxic knowledge of the field and how to play this game more or less effectively (Bourdieu and Wacquant, 1992). Through field membership and socialization, social structures and practices are internalized in habitus, giving rise to multiple taken-for-granted ways of perceiving the world and behaving within it, which are temporally and situationally enduring (Bourdieu, 1990; Bourdieu and Wacquant, 1992). In this way, habitus provides the mechanism for an individual to understand the field's doxa and to act accordingly within the limits set by both doxa and habitus, providing the individual with a "sense of one's place" in relation to the other field members (Bourdieu, 1987: 5).

Consensus between field members of an organization's doxic rules as legitimate and its rewards as valuable and desirable occurs through shared habitus, created via "supra-individual dispositions capable of functioning in an orchestrated or, one could say, collective way" (Bourdieu, 2000: 156). These collective dispositions result from individuals occupying homologous positions within a field and sharing similar socialization experiences, such as practitioners within a specific HR department or, more broadly, within the HRM profession. Through shared habitus, social practices become immediately understandable and predictable to similarly situated individuals, such as how an HRP might respond to bullying. However, one consequence of shared habitus is that individuals become less critical and reflective of their own and each others behaviour. Consensual taken-for-granted practices become endowed with a sense of objective commonsense negating the need for "close analysis of the nuances of another's practice" (Bourdieu, 1977: 80). This unquestioned acceptance contributes 
to certain practices becoming spontaneously thinkable and, therefore, accessible, whilst others become unthinkable and inaccessible (Emirbayer and Johnson, 2008).

Language, and its use, contributes to this process. Predominantly through their language, more powerful members determine the field's structure and rules and the way that less powerful members perceive the field and behave within it: Bourdieu (1991) calls this dominance through language, symbolic violence. It is the process by which the importance of economic capital is disguised by its transformation into symbolic capital. By virtue of their legitimized symbolic capital and the control they have over the valued resources in the field, powerful field members assert their voice and view of the world. Symbolic violence is not transparent to less powerful field members, because of the taken-for-granted nature of symbolic capital and because of the process of euphemization, which serves to transform, sanction and censor certain forms of language, which become accepted as part of doxa (Bourdieu, 1977; 1991). Hence, the unconscious dispositions of habitus and the taken-for-granted legitimacy of doxa and symbolic capital together serve to perpetuate the power relations and positions in a field via symbolic violence, to which language is central (Bourdieu, 1987). We return to this important issue below in relation to the critical discourse analysis undertaken during this study.

\section{Methodology}

Seventeen HRPs participated in the research, 14 in interviews (one to two hours), and three in a group interview (two hours). Appendix 1 provides the demographics of the sample. The mean age of the interviewees was forty years, and the mean number of years of HRM experience was fifteen. This reflects a significant level of HRM 
practice, with most having in excess of 10 years HRM experience. A quarter of the sample was male, reflecting the gender split of graduate HRPs in the UK (Ackah and Heaton, 2003), and both the public $(n=$ eight $)$ and the private $(n=$ nine $)$ sectors were represented. Fully informed consent was obtained from all the HRPs prior to the interviews.

The number of participants was determined by saturation: data analysis proceeded concurrently with data collection, and themes identified in later interviews were reapplied to previous data through multiple iterations of analysis. The continued emergence of new or amended themes from this iterative analysis determined the need for additional participants (MacDougall and Fudge, 2001; Wood and Kroger, 2000). Whilst we acknowledge that we can never be sure that gathering additional data will not lead to new insights (Wray et al., 2007), sufficient data was assumed when no new or changed themes emerged from the interviews (Guest et al., 2006), which occurred after 14 (of 17) interviews. The final, group interview acted as quasi-confirmatory stage, deepening the themes that had already been generated from the individual interview analysis.

The data were generated from semi-structured conversational interviews where HRPs were invited to discuss their own experiences of handling organizational bullying claims. In seeking to understand HRPs' lived experience and subjectivity when responding to bullying claims, the focus of the interviews was on how the HRP dealt with the initial claim, regardless of whether the claim of bullying was finally upheld. Whilst acknowledging the debate on the nature of the research interview, and whether the resulting text can be considered as a reflection of the interviewee's own reality or 
whether, instead, it is a reality constructed through the interaction between the researcher and interviewee within the interview context (Potter and Hepburn, 2005, 2007), we contend that theoretically and practically, transcripts of semi-structured interviews provide data on how "ordinary people construct meaning in relation to a particular topic" (Riley et al., 2007; Sims-Schouten et al., 2007; Willig, 2008a: 114). Furthermore, Bourdieu (1977: 79) argued that the taken-for-granted nature of doxa, the struggles for different forms of capital and the dominance exerted by symbolic violence are not transparent to organizational members: "It is because subjects do not, strictly speaking, know what they are doing that what they do has more meaning than they know". Interviews were, thus, deemed appropriate for exploring the language used by HRPs when narrating their experiences of bullying claims. Our analysis explored what their language was attempting to achieve as well as what was actually spoken. Non-linguistic modes of communication, such as the interstices, silences, utterances and emotional tone of the dialogue, were also included as a means to explore underlying thoughts, feelings and behaviours (Willig, 2008a). For example, the use of laughter during speech that is not otherwise meant to be humorous often indicates the speaker's psychological discomfort and may be a device to diffuse tension when delivering messages that would otherwise be experienced as anxiety provoking because the speaker perceives them to be potentially immoral (McGraw and Warren, 2010).

Critical Discourse Analysis (CDA) was chosen as the method of analysis because it locates dominant, taken-for-granted discourses within their socio-historical contexts, reflecting the importance and social function of language as both the mechanism by which individuals interpret and respond to social structures and practices, and the 
means by which analysis may examine their meaning to individuals (Willig, 1999). CDA posits that individual subjectivity is itself a focus for analysis because it is shaped by the subject positions created via discourse. Thus, by situating individuals in their broader socio-historical contexts, CDA allows an exploration of why individuals draw on a range of discourses, and how these might influence their subjective experience and practice (Riley et al., 2007; Willig, 2008b). CDA permits an explicit analysis of Bourdieu's view of language and power, providing the mechanism for exploring how HRPs might create, negotiate and represent their constructions of bullying. Willig's (2008a; 2008b) six-stage process for CDA was adopted and is described in Table 1, illustrating how it was utilized within our Bourdieusian theoretical framework.

Table 1 about here.

A line-by-line approach was taken for the analysis of each interview, and all data were examined; that is, analysis was not restricted to selected sections. Based on the aims of the six stages of analysis (Table 1), coding was applied to phrases and sentences that represented instances of each stage. Both the language and the way in which it was spoken were explored for an indication of the purpose it might be serving for the interviewee's construction of their role and bullying (Sims-Schouten et al., 2007).

For example, in the following excerpt, Clare had just been asked what factors would help her decide if a case was bullying. 
When you are actually dealing with somebody, (1) unless they have actually used that wo::rd $\uparrow$ or that terminology, we, we, we would tend to steer away from it $\uparrow$. You tend to find the minute that you start talking about bullying then that, (1) if anything, if you've got a (2) call them the victim as su::ch (2) we tend to find, (1) certainly in this industry, that (1) there are other issues going on with the people who then, sort of, raise, sort of, bullying allegations $\downarrow$ and that there is other stuff, (1) be it poor performance or something else.

As we see above (the transcription notation key is in Appendix 2), Clare resists using the word bullying, calling it "that word", and "that terminology" (2). In the next sentence (3-7), her pauses (in seconds) indicate that she is taking fleeting thinking spaces (Bollas, 1993) whilst deciding whether to use the word "victim", which she then minimizes with the use of the concessionary phrase "as such" (Lee, 1987). Although she later uses the term "bullying allegations", it is again minimized by multiple uses of the concessionary "sort of" and the lowering tone of her voice (6). She also positions herself as "we" all through her response, rather than "I", suggesting that she is diminishing her own responsibility for her response by identifying with a collective "we" (Harding, 2008). For Clare, this "we" was senior management rather than other HRPs: throughout her interview, her relationship with senior management, particularly the CEO, emerged as an important aspect of her symbolic capital and, thus, credibility and status. Finally, her response provides examples of, firstly, the HRPs' consistent thought that "there must be something else going on" and, secondly, the construction of bullying claims through the lens of performance management (7). Whilst the transcription notation in this excerpt was applied to all data for the analysis, 
to enhance readability they have been removed from the remaining excerpts used in this article.

Although qualitative data are rightly regarded as peculiar to the context from which they were generated, including the dynamics between researcher and participants, Williams (2000) has nonetheless argued that it is possible to draw tentative parallels from qualitative data to other, similar settings. To do so, Williams argues suggests a moderate generalization in which the cultural consistency of the sample must be explicit in the research with clear, relevant links between the research site (the HRPs' organizations) and the site of generalization (other HRPs in similar roles and organizations). In the present study, interviewees were in the field of HRM with experience of handling bullying in private and/or public organizational fields, providing relevance for other HRPs within similar organizational and professional contexts (Leitch \& Palmer, 2010). This extends the likely relevance and applicability of our findings beyond their immediate context.

\section{Findings}

We begin with a brief account of the nature of HRPs' experiences of handling claims within their organizational contexts before presenting data focusing on the interpretive mechanisms used by HRPs when handling manager-to-employee bullying claims. We subsequently illustrate that the predominant response of these HRPs was to reframe bullying claims as situations of poor performance, achieved by using a range of interpretive mechanisms that serve to normalise management behaviour. 
Across the interviews, the HRPs described the complexity and difficulty of handling bullying claims, using words such as "hard", "uncomfortable" and "horrible". Significant was the ambiguity inherent in bullying claims, making it difficult to decide between one person's word against another's. Pressures from the HRPs' organizational and professional fields compounded this challenge: management pressure to resolve claims quickly and protect the organization financially and legally.

The pressures from the HRPs' organizational and professional fields were exacerbated by HR's relative lack of power in comparison to managers, which emerged both explicitly and implicitly from the data. In the following excerpt, Colin, who is an HR Director, describes his sense of powerlessness to challenge managers on their behaviours. He talks about this power imbalance explicitly, and his frequent use of thinking spaces and concessionary phrases suggests that he feels uncomfortable with this situation. His multiple uses of "you know" further suggest that he is seeking the interviewer's endorsement for a circumstance that Colin sees as wrong (7) but feels powerless to change (8-9), and he draws on his experience across multiple organizations to give credence to his belief (4). Colin's excerpt also provides an example of a recurrent tension in the HRPs' narratives: he acknowledges that managers "treat people badly", but avoids labeling the behaviour as bullying $(5,7)$ : In HR though there's not an awful lot you can do about it [bullying], I mean, um, um, we don't have, um, we don't have any direct power to do anything really, you know. You know, we are, we are sort of an advisory, um, function and, um, I've come across a lot in organizations where I've thought oh my goodness and, you know, um, people being treated pretty, pretty badly. Um, but all you can do is say to the manager "look I think that 
person, you've treated that person badly and I don't think you should do it", you know

For other HRPs, the power imbalance with managers emerged more implicitly from their bullying experiences. Whilst many HRPs described being in "partnership" with managers, their experience suggests the symbolic violence implicit within the HRPmanager relationship: the HRPs described deferring responsibility for decisionmaking to managers, positioning their role in claims as providing managers with advice and support. For example, Sonia, who is Head of HR and a Bullying and Harassment officer, is responsible for investigating and deciding the outcome of bullying claims, which is documented in the organization's anti-bullying policy. In the following excerpt she describes handling new claims. Despite her role, Sonia imputes power and responsibility for the investigation and decision to the manager, whilst her role as HR is minimized to "some input" (4). She attempts to justify this approach by her emphasis on "clearly" (3), yet, as with Colin, her language suggests ambivalence: she is not comfortable with the balance of power and she distances herself by moving from the agentive "I" (1) to positioning herself with the impersonal pronoun of "HR" $(4,6)$ : I would, um, I would want the line manager's involvement, you know, because I think it [bullying] isn't an HR problem on its own, you know. It, it, it is clearly a problem that needs line manager involvement as well with, um, some HR input. There needs to be, um, some kind of initial investigation by the line manager, you know, and the line manager should then, um, um, come back to HR to discuss what their findings are. And 
what their findings are, you know, will determine what the future action should be.

(Sonia)

There is an obvious irony here relating to a line manager accused of bullying also being the person to whom HRPs first turn when investigating a claim. Yet despite this power imbalance, the HRPs perceived their predominant alignment with management and their main responsibility to protect the organization and managers. At the same time, the HRPs distanced themselves from supporting employees and from the previous welfare role of personnel, using negative euphemisms such as "pink and fluffy". For example, when describing her alignment, Jane said, "We are not here as a welfare system for employees... you can't be gamekeeper and poacher, you know, you can't be supporting management and at the same time supporting employees, it just doesn't work".

Within this context, we now illustrate how these HRPs immediately invoked a discourse of performance management when presented with new claims of manageremployee bullying, a discourse which underpins the subsequent tranche of data illustrating the mechanisms and euphemisms used by the HRPs to interpret managers' behaviour in these claims and, in doing so, perpetuate a cycle of symbolic violence by enacting it on the target who raised the claim.

Managerial bullying as symbolic violence through performance management practices

A notable and unexpected finding was that all manager-to-employee claims within the HRPs' narratives were constructed within a performance management discourse: 
manager-to-employee claims were interpreted as performance management practices that had been ineptly executed by managers or misunderstood and/or disliked by employees. To illustrate this important finding, in the following excerpts Angela, Sandra and Kath describe how manager-to-employee claims are frequently associated with the management of a performance situation:

“Quite often when someone's performance is called into, quite often they will claim that they're being bullied. That's quite common."

(Angela)

"I've had 100 times more of those kind of claims against managers and I can almost predict that every time the line manager says "I'm really going to deal with this person" that it will result in an allegation of bullying."

'We've seen a definite increase in people challenging when they're being performance managed, raising a claim and then linking that to them being treated differently by their manager."

The HRPs' constructions of manager-to-employee claims within a performance management discourse were characterised by two key aspects. Firstly, across private and public sectors, the HRPs' language was imbued with symbolic violence that reflected a consistent organizational doxa: organizations were described as increasingly target driven; employees were continually required to achieve more; and managers were required to manage this drive for increased employee performance. Secondly, when presented with a new claim of alleged manager-to-employee bullying, there was a surprisingly consistent and immediate manager-centric assumption that 
"something else is going on", as illustrated by Clare's excerpt in the methodology. Below, Teresa reflects on how her organization has become more target driven, positioning herself with the manager as part of the "we" of the organization $(1,5)$. Her language suggests a sense of solidarity and endorsement of the increased targets, and a garnering of increased symbolic capital from alignment with the more powerful managerial group. The employee is positioned throughout as the other with "you". Through the symbolic violence of her language, she imputes culpability for the increase in performance-related bullying to the employees: their feeling of being bullied has arisen from failing to acknowledge their own mistakes or their underperformance in the new target-driven regime (9-12). Yet, tension is apparent in her account: on the one hand, she justifies her approach with words of certainty: there is "always something else" (8-9) and her multiple uses of "actually" (9), and by speaking her rationale as the voice of the organization to the employee (9-11). Yet, uncertainty is evident: she seeks affirmation of her approach with "if you will" (9) and "you know" (6), and minimizes her own conclusion with the concessionary "a little bit" (12):

We are an organization that has become more target driven now. You are accountable; you can't have half a dozen jobs and take all the time you like to do the job. You've potentially got some people who feel bullied because they are expected to reach a certain target, but what the manager is trying to do is to say "we've already established that that is a reasonable amount for anybody to do given your level of experience", you know. For some people that's an environmental culture that they're not happy with any more. Most cases against managers have been about performance improvement plans, and there is always something else in the mix, if you will, that is actually 
making me think "actually, is this just another way of trying to avoid dealing with the fact that you are not performing or you have done something that you shouldn't have done". It feels a little bit as if they are hanging their hat on the word bullying

(Teresa)

Teresa's account illustrates the HRPs' pervasive immediate response to new managerto-employee claims of "what else is going on here?", and the equally commonplace answer of "the employee has a performance issue". In this way, claims were subsequently interpreted as a symptom of the manager's legitimate performancemanagement practices, and bullying as a label for recalcitrant employees to "hang their hat on". From our data, this immediate response to the target's claim, imbued with symbolic violence, occurs at the initial meeting with the target when the HRP is first presented with a new manager-to-employee claim, and this response appears crucial in understanding how HRPs subsequently interpret and euphemise managers' behaviours in these claims.

The HRPs perpetuated the dominance of the managers' perspective through the symbolic violence of their language: using a range of euphemistic labeling, sanitizing language and interpretive mechanisms the HRPs' language served to normalise and rationalise management behaviours that would be defined as (potential) 'bullying' within organizational anti-bullying policy. These mechanisms of symbolic violence enabled the neutralization of toxic management behaviours, negating the need to accord a label of 'bullying' and, thus, removing any power from the targets' voice. Four recurring constructions of managers emerged from our analysis of the data, which the HRPs used as mechanisms to rationalize and neutralize negative 
management behaviours reported by targets: 'Company Manager', 'Inadequate Manager', 'Old School Manager', and 'Untouchable Manager'. These interpretive mechanisms, as we know examine, enabled the HPRs to interpret manager-toemployee bullying claims within the dominant worldview of managers.

\section{Company managers: the "drivers and controllers"}

The HRPs constructed these managers as target-driven and performance-focused. Concomitantly, company managers were often portrayed as lacking self-awareness and insensitive to the needs and responses of their subordinates because of their drive and focus. In the following excerpt, Amy is discussing why she believes there has been an increase in performance-related bullying claims in her organization. Even when managers are insensitive to the impact of their behaviour (7-9), the high drive, ambition and performance of company managers appear to be positively endorsed. Whilst Amy is suggesting that a "good leader" is determined by these behaviours (15), tension is evident in her account as, through the impersonal stance of "you" (5), she questions where the line is between drive ("good") and controlling or bullying behaviour ("bad"). Interestingly, when she talks about "we" not wanting managers to bully, she corrects herself by removing the conditional "necessarily" (6), suggesting that there are times when "controlling" behaviour from managers might be accepted, condoned or unchallenged. Her account, and the existence of a course on listening skills, suggests that she may be aware of the negative impact of behaviours of driven, ambitious managers. Yet, by neutralizing these behaviours as the poor listening skills of "drivers" she is able to challenge and address these behaviours (9-11), perhaps more effectively than if she labeled the behaviour as bullying: 
We've got a lot of people around here who are very, very highly driven and probably quite a lot of people who like to be in control and you've got some ambitious people who want to get on. Well, adding that up you're going to have people who are really pushing all the time to achieve and where it's interesting is where you draw the line between just wanting to achieve, a very good leader, to controlling, not necessarily what we want, well not what we want, to bully. So if you've got a manager, a driver, who is, um, um, not checking for understanding and clarifying that the person is comfortable with how they've been treated, haven't been listening, and if they're not demonstrating those types of skills we would give them the feedback that they're not doing it right and it might well then appear into their personal development objectives.

(Amy)

As this example illustrates, the HRPs' language suggested feelings of dissonance caused by the conflict between the symbolic capital accorded to "good leaders" for their drive and ambition and the awareness that employees may perceive the behaviour of these driven company managers as bullying. Given that tension, this mechanism provided the HRPs with the means of tempering these "good" organizationally sanctioned behaviours without labeling the manager a bully. In contrast, the next mechanism we present is characterized by "poor" management behaviour.

Inadequate Managers: the "crap managers"..

The HRPs euphemised inadequate managers' behaviour as inappropriate, poor or inept, typically because of the manager's lack of skill/training or over-promotion. 
Behaviours that CIPD's (2009) guidance classifies as bullying were instead labeled ineffectual or inept. For example, in the following excerpt Mark recounts a claim of bullying made by several employees against their line manager and the interviewer has asked Mark if he thought it was bullying. In answering, Mark makes the distinction between bullying ("maliciousness") and poor management (being a "crap manager", 1-2), suggesting that the assumed unintentionality of being a "crap manager" may help Mark to resist a label of bullying. However, his thinking spaces and concessionary phrases throughout, particularly his struggle to find the word "maliciousness" (1-2), suggest ambivalence: he may not be completely comfortable with his interpretation, and whilst he uses the manager's ineptitude to explain the bullying behaviours, he is constantly seeking affirmation of his interpretation: And, and I would again, I think, and again, that wasn't down to, um, maliciousness, it's just he was a crap manager, basically. And he knew he was a crap manager and that sort of, that manifested itself in the way he dealt with his people, which was, you know, shouting, balling, um, demanding, unacceptable, you know, sort of demands placed on them, because he couldn't, it was the only way he thought he'd get their cooperation, you know.

(Mark)

Mark's excerpt illustrates how the HRPs used this construction to neutralize bullying behaviours by explaining such behaviour by recourse to poor or inadequate management skill, thus avoiding a label of bullying. In the following mechanism, management behaviour is, again, interpreted as "inappropriate" but specifically because the manager is unable to adapt their management style to meet the requirements of contemporary organizational cultures. 
Old-school Managers: proponents of the "chiller chat"..

Within the 'old-school managers' construct, a specific form of poor management was normalized, that of long-service managers who were perceived as unable to move with the times or cope with the demands placed on them by their increasingly target and performance-focused organizational fields. In the following excerpt, Rob had been asked why he thought there had been an increase in manager-to-employee bullying claims in his organization. On the one hand, Rob attributes these problems to changes in the business and the situations managers have to deal with: it is not their fault. However, his continued use and emphasis on "the manager" $(4,5,6)$ and his use of "exposed by" rather than "exposed to" (3) suggests that he perceives the manager as (partly) culpable for their behaviour: Some managers can't cope with the rapid change that the business is asking for, that then exposes their managerial, managerial capabilities. Therefore because they're being exposed by situations or problems that wouldn't have existed say six months or six years ago, the manager acts under stress, the manager makes the wrong decision, the manager can't cope with the decision so the manager makes a completely illogical or irrational decision based on what he thinks, and therefore these problems do come up. (Rob)

Whilst Rob's example describes 'old-school manager' behaviours that were, arguably, inadequate, there were other examples of more toxic behaviours euphemized as old school. Lucy describes a recent claim that involves an "old fashioned" way of managing, euphemistically and literally called a "chiller chat" (1-2). Although the 
term chiller describes a large walk-in refrigerator, it also portrays the chilling behaviour she describes (4-6). Her account suggests complicity: she knows that chiller chats occur, yet she minimizes their frequency (6-8) and impact as "a bit of a joke", but her concessionary "I suppose really" would suggest conflict: this may not be how she views the behaviour (3). She also attempts to justify the manager's actions by ascribing culpability to the employee: he is "a pain in the arse" who has pushed an otherwise "really good manager" into this infrequent but extreme behaviour (9-11). They [the target] seem to be implying that the manager has had a chiller chat as we call it. So quite an old fashioned way of, um, doing things. They're a bit of a joke in the company now, chiller chats, I suppose really, "Oh we'll take him and we'll have a chiller chat". So that means taking them into the chiller where nobody can hear them, where there's no witnesses and then telling them exactly what you think of them or worse. Um, now I do genuinely believe that chiller chats, they don't go on that often any longer, that's not to say that, you know, I'm being naïve to think that they never happen, yeah. So I think the individual is a pain in the arse and, um, I, I would have thought the manager has possibly told him that. He's a really good manager but I may be think there is a bit of an edge there where he might do something like that.

(Lucy)

As with 'company managers' and 'inadequate managers', the 'old-school' interpretive mechanism repackaged bullying behaviour in a way that enabled the HRPs to challenge managers' behaviour without according the label of bullying. Whilst neutralizing bullying behaviours, these mechanisms enabled the HRPs to take some form of action by speaking to managers about their behaviour under the guise of 
(in)appropriate management behaviour rather than bullying. In contrast, what differentiates the final mechanism is that HRPs were powerless to act in any way.

\section{Untouchable Managers: the "child abusers".}

These managers were those who were 'too senior' or 'too valuable' to tackle, and in the following exchange John discusses a series of bullying claims against "very, very senior" managers. Whilst he acknowledges that the claims are "serious" (1), he minimizes the behaviour with multiple concessionary phrases: it is "kind of" bullying behaviours, "sort of" shouting (2), and "a little bit kind of or not quite right" (7). He begins by positioning himself as "I" when describing the cases, and then distances himself as "you" and "we" when he describes how the behaviour is allowed to continue unchallenged, suggesting he feels discomfort with this stance (5-8). He justifies this economically: these senior managers have sufficient "bank balance", economic capital, which provides implicit permission for them to behave how they wish unimpeded. John seeks approbation for his "bank balance” justification (8-9), again suggesting his dissonance with the untouchableness of these managers:

1 I've been recently involved in cases involving significantly serious claims of kind of bullying behaviours or inappropriate conduct, sort of shouting, unacceptable demands over workload and availability to work, you know, cited against very, very senior individuals. You do see almost an acceptance because the person's always behaved in that way and actually we all might cringe and say "well that was a little bit kind of or not quite right" but, yeah, it, it's just bypassed; whereas if it's someone new, that hasn't got the bank balance, if I can call it that, with the company, then 
we'd be hot onto it and probably we'd sort it out quite quickly.

Similarly, Clare recounts behaviours from senior managers in her organization towards the junior staff, behaviours that she labels as "very, very derogatory". She stalls over telling the interviewer that these senior managers are called "child abusers" (1-3), and her feelings of discomfort with this term and its connotations are signaled by her incongruous laughter and her immediate acknowledgment of how "an outsider", the interviewer in this case, might react to this label. When asked by the interviewer, Clare describes this as commonplace bullying behaviour (11-12), which she rationalizes as a rite of passage, signifying a potential cycle of abuse with senior managers repeating their own experience of being bullied, perpetrated on junior staff who are too "desperate, keen and eager" to complain (6-8). Her sense of powerlessness to tackle this cycle of symbolic violence is imbued within her phrase "It's just the way it works" (14):

1 Clare: [Laughter] everyone knows, when they [senior managers] get to a 2 certain level and everyone will say "oh yeah, he's evil, or he's a....", what we 3 call them, we call them child abusers, which, which I think to an outsider will think "oh God, that's a very strong word to use", but that, that's what you use if somebody senior displays behaviours that are effectively very, very derogatory towards the junior [staff], because the junior [staff] are so desperate to be big senior [staff] they will do anything, they are so keen and so eager they won't complain.

9 Interviewer: And how would you describe that sort of management behaviour? 

and that's, that's what we get a lot of. It's somebody who is abusing their position and in a lot of cases it is "well I had to do it when I was that level so you've got to do it now". It's just the way it works.

Thus, our data suggest frequent ambivalence and discomfort as HRPs attempt to reconcile an awareness and understanding of the targets' subjective experience with their shared HR habitus and a sense of "their place" within their organizational fields. This in turn supports the finding that handling bullying claims is a difficult and complex issue for HRPs. The HRPs' construction of manager-to-employee claims as 'employee under-performance' and the associated interpretive mechanisms for managers' bullying behaviours appear to result from the symbolic violence enacted on HRPs through their relative powerlessness in comparison to managers and the organizational and management pressures to deal with bulling claims in a way that protects the manager. Against this backdrop, the interpretive mechanisms appear to be functional for the HRPs: they enable the HRPs to fulfill their main professional objective of protecting the organization and management, maintaining their sense of symbolic capital, whilst providing the means to challenge managers' behaviours from a position of relative powerlessness.

\section{Discussion: The cycles of symbolic violence in workplace bullying}

The HRPs in this study use four interpretive mechanisms to legitimize and sanitize management behaviour in claims of manager-to-employee bullying - claims that are then interpreted as symptoms of the performance-management process and not as cases of (potential) interpersonal bullying. Our findings have demonstrated that HRPs are not as passive as they are perceived to be by targets, but instead make active 
choices to interpret the behaviours involved in manager-to-employee claims as a lack of interpersonal or management skills on the part of the manager, legitimated by their strident pursuit of high performance in increasingly normalized pressurized workplace cultures. As such, we argue that HRPs' actions represent symbolic violence against employees against the backdrop of institutionally embedded bullying discourses in doxa of increased targets, stretch goals and high performance.

Thus, here we put forward support for the more critical thesis that bullying goes beyond the individual and interpersonal levels, and can be manifest in organizational structures and processes which characterize the organizational fields with which the HRP's professional field intersects (Czarniawska 2008; Rhodes et al. 2010). It is important to note here that we are not suggesting that bullying is never an interpersonal process, rather that 'organizational bullying' may also exist by virtue of the power systems and structuring process inherent in organizations, which may be a crucial aspect in the escalation of conflict. (Liefooghe and MacKenzie Davey, 2010). We are not seeking to exonerate managers for bullying behaviours in a move akin to a 'Nuremberg Defence' but to suggest how these behaviours come to be treated as acceptable by HRPs, as evidenced in our data, as rational responses to the symbolic violence enacted upon them by the wider field of capitalist organization. We use this analysis to conclude the paper by considering the impact this has on targets' experiences of raising bullying claims against their manager and the likely prognosis for tackling workplace bullying more broadly.

\section{Organizational Bullying}


From this perspective, targets, appraisals, surveillance mechanisms, and measurement are constitutive of the discourses that underpin cultures of performance management. All these instruments were invoked by the HRPs in this study in various ways as they 'explained away' the potentially bullying behaviours of managers. In so doing, they (perhaps unwittingly) occlude other equally legitimate concerns such as the right to fair and dignified treatment at work. Our position here echoes Czarniawska's (2008: 1052, our emphasis) straightforward statement:

Let me therefore be as clear as I can: even if humiliation was very good for business, it should be prevented and condemned because it is morally wrong.

This concept of 'organizational bullying' is not new; in 1976 Carroll Brodsky published a book in the USA called "The Harassed Worker", based on his therapeutic work with targets of bullying. He argued that bullying had become a "part of most management systems" to control employees (Brodsky, 1976: 7) and that management was, therefore, at the basis of all bullying by initiating, supporting or failing to prevent it. However, importantly for our purposes here, Brodsky postulated that power is not simply vested in individuals through the legitimacy of hierarchy or social influence; it is enacted through the discourse surrounding organizational practices which privilege management whilst muting the voice of the employee (Liefooghe and MacKenzie Davey, 2001). Evidenced by their own narratives, our data suggest that HRPs' responses to employees in these claims are indeed inaction, denial, targetblaming or management complicity. The following sections elucidate further on how this plays out in practice. 
Constructing manager-to-employee claims as 'performance-related' and engaging the associated interpretive mechanisms may be functional for the HRPs, since their constructs and interpretive mechanisms limit their available roles and practices when responding to bullying claims. This repackaging of potentially bullying behaviours into "inappropriate management" enables the HRP to talk to managers about "more appropriate' ways of behaving without damaging their own relationship through accusing the manager of being a bully. In doing so, the HRP positions her/himself as a useful and expert business partner to management in dealing with bullying claims; whether this is a view shared by managers, of course, requires further research. Thus, whilst the repackaging protects the manager, and indirectly the organization, it also benefits the HRP who gains symbolic capital through their value in contributing to the economic and legal protection of the organization.

The one party that does not appear to benefit, is the employee who raised the bullying claim. The data suggest that the HRPs' strong management-alignment within professional habitus eliminates their ability to engage in employee advocacy, as found in other HRP role contexts (e.g., Keegan and Francis, 2010). The HRPs in this study were explicit that they were not "social workers" and could not be both "gamekeeper and poacher" by supporting managers and employees. Casting doubt on the 'truthfulness' of the target's perception of bullying negates the need to even consider the target's feelings of being bullied and, hence, engage in employee advocacy. The HRPs are able to protect themselves from management criticism, as well as avoid the dissonance and self-conscious emotions that would be associated with acknowledging the target's subjective experience. Here, we provide a caveat: no assumption is being made as to whether the claims in these narratives are 'genuine bullying' - this is not 
possible to ascertain from the only the HRPs' perspectives in these data. Whether or not the claims were 'true', the crucial issue is that these HRPs did not explicitly verbalize the consideration that the claims were potentially bullying during the interviews, or that the behaviour could be perceived as bullying by the targets, even when the management behaviours described by the HRPs would have met organizational definitions of bullying (e.g., CIPD, 2009), or were euphemized with labels such as "child abuser", which are heavily imbued with negative emotion and values. Whilst the moments of dissonance and discomfort that we identify in our data may suggest that the HRPs are aware of the nature and impact of managers' bullying behaviours, it is the observed lack of overt consideration and acknowledgement that could be crucial in understanding targets' perceptions of HRPs' inaction (e.g., Hutchinson et al., 2009).

As we established in our review of workplace bullying, the labeling of behaviours as potential 'bullying' is vital for an employee to receive the support and protection of the organization's anti-bullying policy. HRPs are the gatekeepers of policy and bullying investigations and if all manager-to-employee claims are outwardly labeled and responded to as 'performance issues', the employee's expectations of support and justice from using the anti-bullying policy are unlikely to be met. By refusing to acknowledge the potential of bullying, the HRP - through the symbolic violence within these mechanisms - is protecting the organization, making it appear that bullying simply does not occur, and denying the employee the right to invoke a policy specifically designed to protect them from such behaviours. 
Ulrich and Brockbank (2005) state that employee advocacy is a cornerstone of the contemporary HR function, in the UK at least, and whilst we are not so naïve as to believe HRM exists for the good of employees, we nonetheless find the lack of employee advocacy demonstrated in our data particularly ominous for bringing about change. Given the increasingly non-unionized character of many workplaces (particularly in the US and UK), the demise of collective bargaining and representation, along with the individualization of the employment relationship (Hoel and Beale, 2006), we ask who exactly is tasked with the traditional 'welfare' role of protecting employee wellbeing at work aside from their eventual recourse to the law? If HRPs, by virtue of their positioning in organizational and professional fields, are unable to respond as employee advocates, cannot listen to the employee's subjective experiences and therefore are condemned - through the mechanism of symbolic violence - to 'excuse' managers' behaviour as 'acceptable', how can the perniciousness of bullying ever be tackled?

\section{Conclusions}

The data presented here suggest that, at present, explicitly tacking management bullying is an almost impossible course of action for HRPs within their current organizational and professional fields. Whilst we acknowledge the limitations of drawing conclusions from analysis of interview data from a small sample, issues which we have addressed in our method section, we contend that the consistency of the emergent themes across interviews are worthy of moderatum generalization (Williams, 2000). Thus we conclude the paper by suggesting future research agendas to further advance our understanding of the dynamics of manager-to-employee workplace bullying in order to effectively address it. On one level, the suggestions we 
make below, sit uneasily with our critical agenda since they do little to challenge the underlying discourses of managerialism and target-driven performance management that reinforce the ascendancy of economics in organizational settings to the detriment of everything else. As Armstrong (2011) and Rhodes et al. (2010) suggest, nothing short of revolution in the underpinnings of capitalist organizations is needed to address the structural antecedents for organizational bullying. We do concur with this observation, because our data evidences that 'performance management cultures' driven by the paradoxical need for higher productivity at ever-lower cost - legitimize and excuse the 'bullying behaviours' of individual managers. But we also tentatively suggest that the only way to subvert and produce change may be from within the very discourses we seek to change.

Firstly, if HRPs cannot be disentangled from line management, we suggest a new independent role may be needed to deal with claims of bullying. It is noteworthy that some large institutions have implemented ombudsman schemes (e.g., Harding, 2009), where neutral officers handle complaints. It is possible that we are observing the start of a change in structures and systems to reflect gaps in practice (such as the employee advocate role) as have been found in our data and further research to support the instigation and operation of an independent function is to be welcomed.

Secondly, we also took encouragement from observing the HRPs' moments of ambivalence, manifested as apparent discomfort in the interviews. These 'sticky moments' (Riach, 2009) reveal themselves in our data, for example, through the shifts from "I" to "we" that show HRP's desire to distance themselves from certain positions (e.g., Sonia, John); requests for the interviewer's affirmation of potentially 
problematic sentiments (e.g., Teresa, Mark); and techniques to diminish the seriousness of the subject matter through incongruous laughter, conjecture or concessionary phrases (e.g., Lucy, John, Clare). Perhaps these points of tension and discomfort may suggest chinks in the armour through which it might be possible to encourage HRPs to consider the target's perspective in bullying claims and challenge management behaviour more explicitly. In the UK, for example, it is arguably within the CIPD's power to reconsider its approach to the profession and rebalance the interests of employees and management within HRP roles.

Given the function of the CIPD as a primary source of professional socialization for HRPs, it could emphasize this balance in its publications and accredited courses, training HRPs to recognize and act on the ethical implications of all stakeholder needs and providing the skills to challenge unethical behaviour. Doing so could strengthen the professional field over the organizational one for HRPs. It would require the CIPD to reconsider its positioning of HRPs as apparently uncritical supporters to line managers, instead strengthening HRPs' very real capability to make judgments as HR professionals that might contradict and challenge line managers, thus increasing their capital. Further research would of course be needed, but the "sticky moments" of disquiet we observed in our data may provide real opportunities for action.

\section{References}

Ackah C and Heaton N (2003) Human resource management careers: different paths for men and women? Career Development International, 8: 134-142. 
Armstrong P (2011) 'Budgetary Bullying' Critical Perspectives on Accounting, forthcoming

Beale D and Hoel H (2010) Workplace bullying, industrial relations and the challenge for management in Britain and Sweden. European Journal of Industrial Relations, 16: 101-118.

Bollas C (1993) Being a character: Psychoanalysis and self experience. London: Routledge.

Bourdieu P (1977) Outline of a theory of practice. Cambridge, UK: Cambridge University Press.

Bourdieu P (1986) The forms of capital. In: Richardson JG (ed) Handbook of Theory and Research for the Sociology of Education. New York: Greenwood Press, pp. 241258.

Bourdieu P (1987) What makes a social class? On the theoretical and practical existence of groups. Berkeley Journal of Sociology, 32: 1-17.

Bourdieu P (1990) The Logic of practice. Cambridge, UK: Polity Press.

Bourdieu P (1991) Language and symbolic power. Cambridge, UK: Polity Press.

Bourdieu P (1993) Sociology in Question. London: Sage

Bourdieu P (2000) Pascalian meditations. Cambridge, UK: Polity Press.

Bourdieu P (2001) Masculine domination. Stanford, USA: Stanford University Press.

Bourdieu P and Wacquant L (1992) An invitation to reflexive sociology. Chicago, Il: University of Chicago Press.

Brodsky C (1976) The harassed worker. Lexington, MA: Lexington Books. 
CIPD (2012) Harassment and bullying at work. Available at:

http://www.cipd.co.uk/hr-resources/factsheets/harassment-bullying-at-work.aspx (accessed 27 January 2013).

CMI (2008) Bullying at work 2008: The experience of managers. London: CMI.

Czarniawska B (2008) Humiliation: A standard organizational by-product. Critical Perspectives on Accounting, 19: 1034-1053

D'Cruz P and Noronha E (2010) The exit coping response to workplace bullying: the contribution of inclusivist and exclusivist HRM strategies. Employee Relations, 32: 102-120.

Dobbin F (2008) The poverty of organizational theory: Comment on: Bourdieu and organizational analysis. Theory and Society, 37: 53-63.

Einarsen S and Hoel H (2001) The validity and development of the Revised Negative Acts Questionnaire. 10th European Congress of Work and Organizational Psychology. Prague.

Einarsen S, Hoel H, Zapf D and Cooper CL (2003) The concept of bullying at work. In: Einarsen S, Hoel H, Zapf D and Cooper CL (eds) Bullying and emotional abuse in the workplace: international perspectives in research and practice. London: Taylor and Francis, pp. 3-20.

Einarsen S, Hoel H, Zapf D and Cooper CL (eds) (2010) Bullying and emotional abuse in the workplace: developments in theory, research and practice ( $\left.2^{\text {nd }} \mathrm{ed}\right)$. London: Taylor and Francis.

Emirbayer M and Johnson V (2008) Bourdieu and organizational analysis, Theory and Society, 37: 1-44.

Ferris PA (2004) A preliminary typology of organisational response to allegations of 
workplace bullying: see no evil, hear no evil, speak no evil. British Journal of Guidance and Counselling, 32: 389-395.

Giga SI, Hoel H and Lewis D (2008) Dignity at Work: The Costs of Workplace Bullying. Unite and BERR Partnership Project Working Together for Dignity at Work. London: Unite the Union/BERR.

Gilmore S and Williams S (2007) Conceptualising the "personnel professional": A critical analysis of the Chartered Institute of Personnel and Development's professional qualification scheme. Personnel Review, 36: 398-414.

Guest G, Bunce A and Johnson L (2006) How many interviews are enough? An experiment with data saturation and variability. Field Methods, 18: 59-82.

Harding N (2008) The "I", the "me" and the "you know": identifying identities in organisations. Qualitative Research in Organizations and Management: An International Journal, 3: 42-58.

Harding T (2009) Military commanders must investigate bullying, commissioner says. The Telegraph. Available at:

www.telegraph.co.uk/news/uknews/defence/4938473/Military-commanders-mustinvestigate-bullying-commissioner-says.html (accessed 28th May 2012).

Hoel H and Beale D (2006) Workplace bullying, psychological perspectives and industrial relations: Towards a contextualized and interdisciplinary approach. British Journal of Industrial Relations, 44: 239-262.

Hogh A, Mikkelsen EG and Hansen AM (2010) Individual consequences of workplace bullying/mobbing. In: Einarsen S, Hoel H, Zapf D and Cooper CL (eds) Bullying and emotional abuse in the workplace: developments in theory, research and practice ( $2^{\text {nd }}$ ed). London: Taylor and Francis, pp. 107-128.

Hutchinson M, Vickers MH, Wilkes L and Jackson D (2009) “The worse you behave, the more you seem to be rewarded": bullying in nursing as organizational corruption. 
Employee Resonsibilities and Rights, 21: 213-229.

Jenkins R (2002) Pierre Bourdieu (2 ${ }^{\text {nd }}$ ed.). London: Routledge.

Keegan A and Francis H (2010) Practitioner talk: the changing textscape of HRM and emergence of HR business partnership. International Journal of Human Resource Management, 21: 873-898.

Lee D (1987) The semantics of 'just'. Journal of Pragmatics, 11: 377-398.

Lewis D and Rayner C (2003) Bullying and human resource management: a wolf in sheep's clothing? In: Einarsen S, Hoel H, Zapf D and Cooper CL (eds) Bullying and emotional abuse in the workplace: international perspectives in research and practice. London: Taylor and Francis, pp. 370-382.

Liefooghe APD and MacKenzie Davey K (2001) Accounts of workplace bullying: the role of the organization. European Journal of Work and Organizational Psychology, 10: 375-393.

Liefooghe APD and MacKenzie Davey K (2010) The language and organization of bullying at work. Administrative Theory and Praxis, 32: 71-95.

Lutgen-Sandvik P (2008) Intensive remedial identity work: Responses to workplace bullying, trauma and stigmatization. Organization, 15: 97-119.

MacDougall C and Fudge R (2001) Planning and recruiting the sample for focus groups and in-depth interviews. Qualitative Health Research, 11: 117-126.

McGraw AP and Warren C (2010) Benign violations: Making immoral behaviour funny. Psychological Science, 21: 1141-1149

Ozbilgin M and Tatli A (2005) Understanding Bourdieu's contribution to organization and management studies. Academy of Management Review, 30: 855-869. 
Painter J (2000) Pierre Bourdieu. In: Crang M and Thrift N (eds) Thinking Space. London: Routledge, pp. 239-259.

Rayner C (2005) Reforming abusive organizations. In: Bowie V, Fisher BS and Cooper CL (eds) Workplace violence: issues, trends, strategies. Cullompton, Devon: Willan Publishing, pp. 60-74.

Rayner C and Lewis D (2010) Managing workplace bullying: the role of policies. In: Einarsen S, Hoel H, Zapf D, Cooper CL (eds) Bullying and emotional abuse in the workplace: developments in theory, research and practice $\left(2^{\text {nd }} \mathrm{ed}\right)$. London: Taylor and Francis, pp. 327-340.

Rayner C and McIvor K (2008) Research report on the Dignity at Work project. University of Portsmouth, Portsmouth Business School, Portsmouth.

Rhodes C, Pullen A, Vickers MH, Clegg SR and Pitsis A (2010) Violence and workplace bullying: what are an organization's ethical responsibilities. Administrative Theory and Praxis, 32: 96-115.

Riach K (2009) Exploring participant-centred reflexivity in the research interview. Sociology, 43: 356-370.

Riley SCE, Sims-Schouten W and Willig C (2007) The case for critical realist discourse analysis as a viable method in discursive work. Theory and Psychology, 17: 137-145.

Salin D (2008) The prevention of workplace bullying as a question of human resource management: measures adopted and underlying organizational factors. Sandanavian Journal of Management, 24: 221-231.

Salin D (2009) Organisational responses to workplace harassment: an exploratory study. Personnel Review, 38: 26-44. 
Scheuer J (2003) Habitus as the principle for social practice: A proposal for critical discourse analysis. Language in Society, 32: 143-175.

Silverman D (2005) Doing qualitative analysis: A practice Handbook. London: Sage.

Sims-Schouten W, Riley SC and Willig C (2007) Critical realism in discourse analysis. Theory and Psychology, 17: 101-124.

Swartz DL and Zolberg VL (2004) Introduction: Drawing inspiration from Bourdieu. In: Swartz DL and Zolberg VL (eds) After Bourdieu: Influence, critique, elaboration. Dordrecht, The Netherlands: Kluwer Academic, pp. 1-13.

Ulrich D and Brockbank W (2005) The HR value proposition. Boston, MA: Harvard Business School Press.

Williams M (2000) Interpretivism and generalisation. Sociology, 34: 209-224.

Willig C (1999) Beyond appearances: a critical realist approach to social constructionist work. In: Nightingale DJ and Cromby J (eds) Social constructionist psychology: a critical analysis of theory and practice. Maidenhead, UK: Oxford University Press, pp. 37-51.

Willig C (2008a) Introducing Qualitative Research in Psychology. Maidenhead, Berkshire: Open University Press.

Willig C (2008b) Discourse analysis. In: Smith JA (ed) Qualitative psychology: A practical guide to research methods $\left(2^{\text {nd }}\right.$ ed). London: Sage, pp. 160-185.

Wood LA and Kroger RO (2000) Doing discourse analysis: Methods for studying action in talk and text. London: Sage. 
Wray N, Markovic M and Manderson L (2007) "Researcher saturation": The impact of data triangulation and intensive-research practices on the researcher and qualitative research process. Qualitative Health Research, 17: 1392-1402. 